\title{
The Use of Technology in Newsgathering
}

\author{
Ben Odeba ${ }^{1}$, Ruth Barnabas ${ }^{2} \&$ Misal Bello Daburi ${ }^{3}$ \\ ${ }^{I}$ Directorate of Academic Planning, Bingham University, Karu, Nigeria \\ ${ }^{2}$ Office of the Deputy Vice Chancellor, Bingham University, Karu, Nigeria \\ ${ }^{3}$ Directorate of Public Affairs, Bingham University, Karu, Nigeria
}

\begin{abstract}
Aerial Newsgathering or Drone Journalism is the use of drones for newsgathering and reporting with the application of Unmanned Aerial Vehicles (UAVs) or Unmanned Aircraft System (UAS) in covering conflict, civil unrest and disaster. Anchored on the Diffusion of Innovation Theory, this paper, "The Use of Technology in Newsgathering" analytically reviewed the concept of aerial newsgathering or drone journalism, otherwise called UAVs. The review shows that 'drone' which was originally created for military operations has now been adopted for civilian use such as journalism especially in potentially hostile environments in order to minimizeor prevent loss of human journalists on the line of duty and other dangers of using human journalists in dangeroussettings. The reviewfurther indicates that 'Drone Journalism' is one of the recent technologies adopted in journalism practicewhich helps to reduce or minimize the killing of human journalists who areexposed to dangers in their line of duty especially during wars and other potentially risky incidences of man-made and natural disasters such as floods, wild fires, storms, earthquakes, and civil unrest. The review also shows that while 'drone technology' is an amazing innovation in both militaryand media organizations, journalism practitioners should be mindful of operational guidelines such as ethics, sovereignty issues, privacy and safety.
\end{abstract}

Keywords: AerialNewsgathering, Contemporary Era, News Reporting

\section{INTRODUCTION}

A dvancement in digital technology is constantly changing the way people do things all over the world; leaving the users with the challenges of how to cope with the changes. In media practice, the practitioners are not only faced with the changes in technology but they are also confronted with both the natural and man-made disasters which have claimed the lives of many journalistson the line of duty.Not only that, human newsgatherers and reporters in the quest for not just newsworthy stories but also factual and objective reportage are confronted with digital development in the media with the challenges each development brings in the course of newsgathering and reporting in the $21^{\text {st }}$ century. And like the proverbial "eneke, the bird", in 'Things Fall Apart', a novel written by China Achebe says, "since hunters have learnt to shoot without missing, "eneke" has also learnt to fly without perching". In the same vein, since the "ills" bedeviling newsgathering and reporting in the contemporary era have refused to abate, media practitioners have also learnt to adopt all available digital technologies for newsgathering and reporting in order to minimize the huge hazards journalists face every day in their primary responsibilities of objective and factual dissemination of information. For instance, on
July 23, 2019, a corps member serving with Channels Television died of gun shots while covering Shite and Police clash in Abuja, Nigeria. This is just one among many cases of the death of journalists during crisis and or conflicts in Nigeria and other parts of the world.

Globally, newsgathering and reporting have witnessed an unprecedented evolution not only as a result of rapid development in digital technology, but also a result of hostile environments where journalists are required to carry out their daily tasks of newsgathering and reporting. One of the most recent developments in journalism is known as aerial newsgathering and reporting. This newsgathering technology is described in many ways; it is referred to as drone journalism, unmanned aerial vehicles (UAVs), unmanned aerial systems (UASs) or newsgatheringand so on. It is the use of aerial technology to gather and report news stories with minimum human control or involvement. The technology is suitable for newsgathering and reporting in hostile environments such as wars, floods, wild fires, storms, earthquakes and civil unrests. Some of the major advantages of or benefits of the use of aerial newsgathering technology or drone journalism include the safety of human journalists, accuracy and speed of operation (Corcoran, 2014).

Studies have shown that newsgathering and reporting in the contemporary era have been befuddled with many daunting challenges. The question is what are the risks journalists face in today's newsgathering and reporting? What are the challenges of newsgathering? In what ways can the challenges be minimized? In journalism, actuality and or reality are hallmarks of a news story. The challenges of contemporary newsgathering and reporting are both natural and man-made; the man-made challenges among others include socio-cultural, political and legal issues. Foremost, there is the need to consider the safety and security of the newsgatherer and the news reporter, privacy issues vis-à-vis government restrictions and legal considerations. The technologies available, their costs and application should also be considered.Newsgathering and news reporting have gone through several stages of evolution and there seems to be so much more tobe desired as advancement in technology continues to soar.

Human newsgathering and reporting have had to face series of natural and man-made disasters; ranging from wars, floods, fires, civil unrest to mention but only a few of them.Drone journalism has revolutionized journalism in the contemporary era of newsgathering and reporting. This is the world satellite 
newsgathering and reporting. The next revolution in satellite newsgathering which enables journalists to gather and report news without endangering human journalists is the use of unmanned aerial vehicles (UAVs) or drone technology (Corcoran, 2014).

\section{Methodology}

This study adopts analytical review of the main concepts with secondary data; journal articles, textbooks, and interaction with experts in the subject matter as instruments for eliciting data for the study.The researcher uses the following questions to guide the study: What was? What is? AndWhat will be?

\section{THEORETICAL FRAMEWORK}

\section{Diffusion of Innovation Theory}

Diffusion of innovation is a theory that seeks to explain how, why and at what rate technology and new ideas or innovation spread and how the diffusion or spread of such innovation affect the micro and macro social systems. Its four (4) main elements include innovation, communication channels, time and social system. However, the effectiveness of diffusion of innovation depends to a large extent on the availability and accessibility of the mass media as well as the language used by the mass media to diffuse or spread the innovation to both the micro and macro social systems.

Everest Rogers (1962) developed the Diffusion of Innovation Theory which originated in communication to explain how an idea, product or communication technology gains momentum and diffuses or spreads over a period of time. The expected result or the main assumption of this theory is that, as part of the social system, people should adopt the new idea, behaviour, product or technology as it is being introduced. Adoption suggests or means that the micro and macro social systems begin to do something differently, or changes behaviour from the previous ones because they believe or perceive the ideas, behaviours, products and or technology as new-fangled or innovation. Social media (Web 2.0) is an emerging or one of the most recent developments or advancements in digital communication media or Information and Communication Technology (ICT) that has bridged all the gaps or barriers between the traditional media and the audience, stakeholders and publics of an organization. It has spread or diffused over the last few decades and is making tremendous changes in relational dialogic communication process. Its impacts on the micro and macro social systems are increasing by the day (Kaplan, 2013).

The Diffusion of innovations theory is a hypothesis outlining how new technological and other advancements spread throughout societies and cultures, from introduction to wideradoption. The diffusion of innovations theory explains how and why new ideas and practices are adopted, with timelines potentially spread out over long periods. Rogers (1962) illustrates the five stages involved in the decision-making process of new innovation thus:

Figure 1: A diagram showing the stages of decision making for adoption of new innovation.

\section{Five Stages in the Decision Innovation Process}

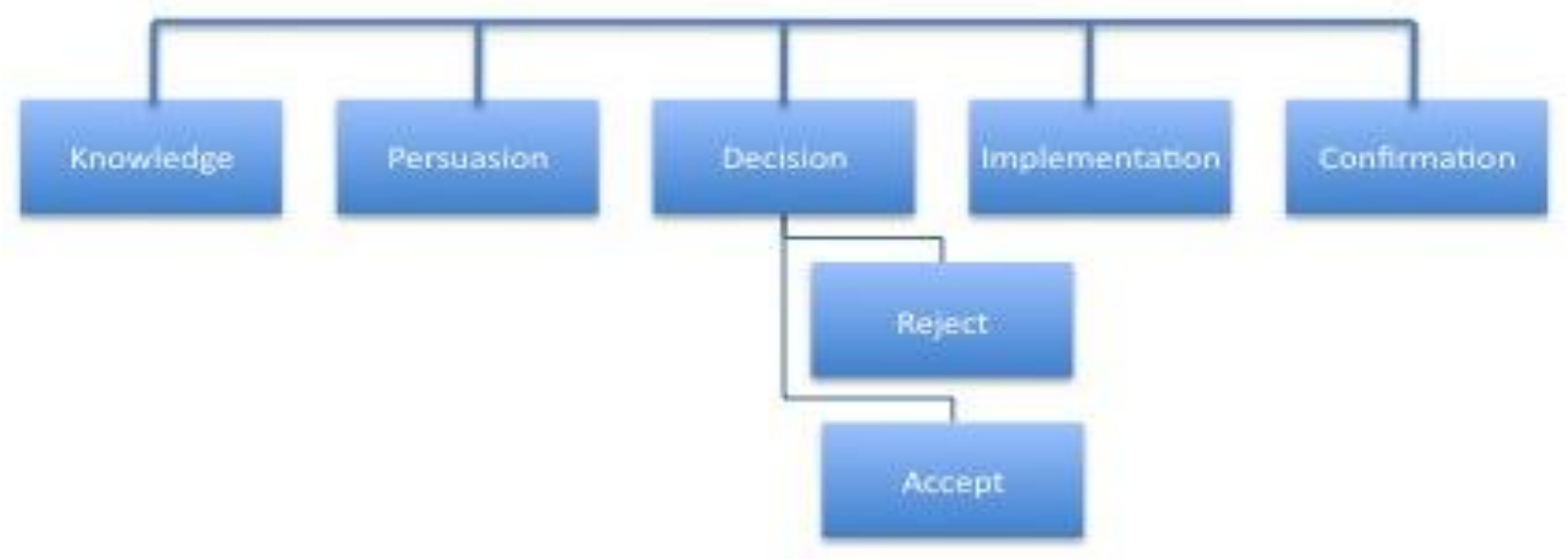

Source: By Rogers Everett - Based on Rogers, E. (1962). 
The knowledge of the new technology or innovation is the first stage in the decision process. The implication of this is that people should be aware of the new innovation or technology before they can think of taking a decision as to whether or not they would adopt it. Persuasion is the next stage where people are encouraged or influenced to adopt or accept the use of the new innovation or idea. Being fully persuaded or convinced to use a new idea or technology, a decision canthen be made as to whether or not to accept or reject. After an innovation is accepted comes the implementation stage and subsequently a confirmation as to its claims or promise as to what it can achieve or help the user to accomplish.

Rogers (1962) further illustrates the adoption of the new technology by different groups of consumers with a curve thus:

Figure 2: Successive Groups of Consumers Adopting the New Technology

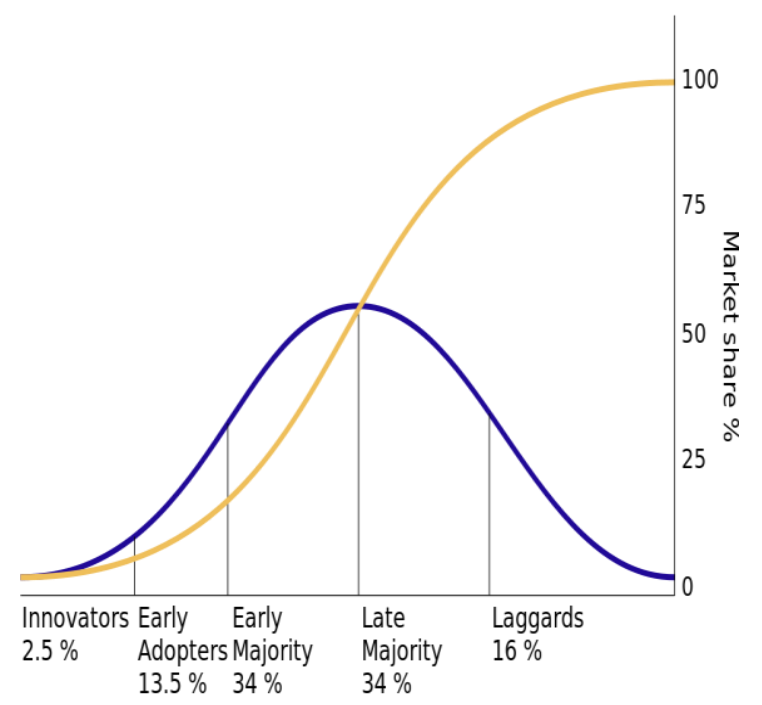

Source: By Rogers Everett - Based on Rogers, E. (1962)

The adoption curve shows that different people show different behaviour towards adoption of a new idea, behaviour, product or technology. It is obvious from the curve that some people adopt idea or behaviour sooner than the others. Roger's theory by this curve shows that in order to promote a wide spread of a phenomenon or behaviour such as this, there is need to market it to each adopter group differently using the available communication channels and messages.

The innovators are the smallest $(2.5 \%)$ but very important group because they are always the first to learn and adapt the innovation. The innovators are responsible for introducing the innovation to the larger population because they share their experiences with their family, friends and the communities. The early adopters are also small (13.5\%), forward thinking group and are often highly respected as opinion leaders in the society. The early majority (34\%) take time to make decisions. They observe other people's experiences for a period of time and adopt the products only when they are convinced that there is real benefit for the new status quo. The late majority (34\%) are more resistant to change. They want innovation to be well tested before they risk trying it out. The last group in the adoption of innovation is called the laggards. Laggards are highly resistance to change as they are hard to reach. They wait until the innovation is completely mainstreamed before they adopt.

The implication is that, it is one thing to introduce a new innovation or idea, it is yet a different thing for its adoption or implementation to happen. Since it takes a lot of efforts from knowledge or awareness about the innovation to persuasion, decision making, and eventual implementation. Unmanned Aerial Vehicles (UAVs) or drone technology is not an entirely new innovation. It has been in existence for more than a decade now. However, its adoption has not reached appreciable level yet especially in developing nations such as Nigeria.

Like every other theory, the strengths of the diffusion of innovation theory include several reviews and contributions to its adoption process which makes the theory relevant in today society. The theory is also an improvement on the earlier limited effects theory. It draws from the existing empirical generalizations and synthesized them into a coherent, insightful perspective. It is practical and lays foundation for several promotional communication and marketing theories and the campaigns they support till date. As per the weaknesses of the theory, diffusion of innovation theory does not take into consideration the resources or social support of the micro and macro social systems to adopt the new behaviour or innovation neither does it help to stop or prevent behaviour, rather, it mainly helps or works better with adoption of new idea or behaviour(Rogers, 2003). In other words, diffusion and adoption of innovation constitute an issue to handle when a new technology is introduced to take care of certain situations or solve problems in the society.

Other issues associated with the use of technology particularly, unmanned aerial vehicles (UAVs) for journalism in the contemporary era evolves from the advancement in drone technology to gather, process and disseminate news. Covering incidences of wars, floods, and many other forms of natural and man-made disasters requires the use of UAVs to ensure the safety of human journalists in such risky and hazardous environments. These among others make Diffusion of Innovation Theory relevant to this study, hence, it is reviewed and used to anchor the paper, irrespective of its time frame.

\section{LITERATURE REVIEW}

\section{The importance/merits of drones in newsgathering}

Drones are also technically called unmanned aerial vehicles or UAVs. The use of UAVs for newsgathering has a lot of merit such as the safety of the journalist, it is cheaper, has high 
quality picture resolution and video to mention only a few. The article titled "Drone Journalism:

Newsgathering Application of Unmanned Aerial Vehicles (UAVs) in Covering Conflict, Civil Unrest and Disaster", by Mark Corcoran (2014) forms the main literature for review and discussions in this paper.The study discusses the use of technology to cover newsworthy events or incidences which pose high risks to the life of human journalists to undertake. The article focuses mainly on the adoption of unmanned aircraft technology for gathering news in unsafe environments which has been characterized in to major conflict, civil unrest and disaster coverage.

\section{Other Uses of UAVs}

UAVs are used in East Asian countries such as Japan, Korea and China, not only for newsgathering but also for application of pesticide on small and medium size farms. Xiongkui, et al (2017) did a study on the use of UAVs for pesticide Application. the study confirms the adoption of UAVs or drones as alternative to manned aerial, its low-cost and efficiency. Its adoption rate is at the development stage in China and Japan. This study was done in China with comparations to what obtains in the neighbor countries such as Japan and south Korea.

Drones are used for other purposes other than newsgathering. For instance, in South Africa, and other parts of Africa, UAVs are used for medical delivery at emergency scenes and other remote areas where there is need for them. "Paradoxically, the use of UAVs to conveyanceof medical samples had been proven in South Africa", Monk highlighted. This had been done in trials by University of the Witwatersrand Professor Barry Mendelow in 2008. But South African Civil Aviation Authority regulations at that time did not allow this to be done on a regular basis, only experimentally.

Comparatively, the adoption of UAVs for either military or civilian use is higher in Europe, America and Asia than those of the African countries. It expected that use of drones in Africa for both the military and civilian operations will increase as the awareness about the benefits deepens. The growth and expansion of aerial technology for newsgathering and reporting is on the increase. This is a relatively new innovation in journalism practice globally, with a higher level of adoption in Europe and Asia. The use of drones for newsgathering is comparatively slower in Africa. While some countries in Africa totally embraced the use of drones, some others are not favorably disposed to the use or adoption of drones for journalism practice. For instance, research has shown that Kenya has a complete ban on drone journalism Lauk, et al, 2016).

According to Perreault and Ferrucci (2020), shows that the use of drones is faced with plethora of challenges ranging from legal, ethical and technical issues. In addition to the regulatory hurdles and privacy issues, there is also the conflict of transition from military use to the adoption of UAVs or UAS for civilian use.

Apaper presented byAzza Ahmed, of Zayed University, United Arab Emiratesduring MediAsia2021Conferenceshows that digital media verge for sharing news since anyone can post links, comment on stories and even create their own content. In other words, digital technology enables access to news stories and helps users to also participate actively in news gathering and dissemination. Furthermore, a 2016 Pew Research Center survey found that $62 \%$ of US adults obtained news via social media, compared to $49 \%$ in 2012 . This shows an exponential increase in the use of technology for news gathering, processing, dissemination and consumption of news stories across the world, particularly in the US.The results of the study by Azza Ahmed, Zayed (2021) show that $67 \%$ of the sample intensively share news via social media. According to the author respondents rated themselves very high in fact-checking and using of credible news sources.

\section{Other Experts}

The author draws from the skillful examination of Michael Cox who is a former senior ABC-TV cameraman. According to the author, Michael has vast experience in conflict newsgathering and he is thecurrent Acting Production Resources Manager which made him responsible for assessment and acquisition of news gathering technology. Secondly, the author features retired

Lieutenant Colonel Philip Swinsburg that plays a vital role in the introduction of small "tactical UAV" surveillance capability for Australian Defence in Iraq and Afghanistan. The author uses the resources of other researchers as well as his personal experience. The implication of this part of the review is that it traces the original application of unmanned aerial vehicles (UAVs) which is

military surveillance. The other implication of this section of the review is that it shows the importance of an experienced cameraman who is also knowledgeable in the use of UAVs for newsgathering. The viewpoints or opinions of these experts are essential for informed decision about adoption of unmanned aerial systems or unmanned aerial vehicle otherwise called drone journalism.

\section{The Author's first Encounter}

In addition, the author relates his first encounter with drone or unmanned Aerial Vehicle (UAV) during the war between Israel and Hezbollah. On this particular experience, the Israeli fixed-wing UAV did not carry weapon rather it has a highresolution cameras and sensors. Both the Israel and Hezbollah demonstrated that they have drones. The author affirms that this was the first time a non-state entity used drone in a crisis. The author wonders if media organizations could also use drones for the purpose of newsgathering considering the successful use of the drone camera to capture a clear picture of what happened during the war. 
This first-time experience by the authormarks a turning point towards adoption UAV for newsgathering and reporting considering its high-resolution cameras and sensors. The implication of this view by the author is that media organizations are being informed about the capability of the drone technology on the one hand. On the other hand, adoption of UVA for journalism practice has the capacity to protect human journalists from the dangers they are confronted with during crisis.

The other implication of this experience is the possibility of a 'non-state' entity, especially the media organizations, using drones for newsgathering and reporting which is in line with the different stages of adoption of new innovation and technology otherwise referred to as diffusion of innovation theory. Therefore, the theory is not only relevant to this study, it is also application to the adoption of new idea, innovation or new technology in the contemporary era of newsgathering and reporting. Drone journalism, aerial newsgathering or unmanned aerial vehicles (UAVs) has come to change the way, not only the way the military carries out its primary responsibility, but also, journalists and others who have adopted and who should adopt the high-tech for doing their

jobs. However, the main question which this study has addressed or answered is "who has adopted and who has not adopted drone technology for newsgathering and reporting and why? Hence Diffusion of Innovation Theory is used to anchor this study.

\section{The Use of Drones for Remote Warfare and Its Adoption for Journalism Practice}

Based on his experience, the author raises many questions to guide his report which bothers on the use of drones for remote warfare and the possibility of adopting the same technology for journalism practice. This and many other questions are extensively analyzed. The questions also centered on possible social and secrecy issues and the benefits of deploying drones for newsgathering in hostile environments.

The author explains that this form of newsgathering is not new because according to him it was used during American civil war and for many other high-risk events. However, the author explains that the use of droneduring conflict is a complicated proposal and therefore requires indepth investigation because of the large number of media workers who are being killed while carrying

out assignment in hazardous environments. As good as it sounds with all its many benefits, "drone journalism" has a complex and difficult preposition. Several journalists have lost their lives on the line of duty in violent incidents such as wars and civil unrests because many times drones on journalistic assignment are targets as they are suspected to be military drones. This is another aspect or challenge of adopting 'drones' for journalistic practice. This is because of the perception that drones on newsgathering mission can be misrepresented and treated as military drones. The author's experience shows that many drones have been destroyed on account that it poses danger to the military operations during wars and other crisis situations.

The implication of this is that even the use of drones poses danger to the human journalists who use them for their task of covering highly risky incidences, or hazardous events or environments. The further question that arises from this and needs to be answered is, if the use of drones for newsgathering still poses danger to the users, what is the way out? This requires further research into what should be done to protect journalists or prevent UAVs meant for newsgathering in crisis or hazardous environments from being shot down by military. How then can the UAVs which are meant for newsgathering be identified to avoid being shot down? This question raises the curiosity for further investigation; the outcome of which would help the prospective or potential adopters of drone technology for journalism practice to be properly and adequately guided.

\section{The Growth of Drones at International Level}

At the international level, the growth of drone journalism or automated journalism is on the increase and it will soon become indispensable item for news crews and freelancers because of its compelling advantages in the contemporary era of newsgathering and reporting. The author is of the view that automated journalism would become popular all over the world in no distant time because journalists were among the first set of people who started the use of drones or UAVs for their works among the civilians. He further explains that the use or adoption of drone technology is more difficult than it appears.

The author identified two main factors which are responsible for the growth of domestic drone or drone journalism. One of the reasons is the reduction in the manufacturing and supply of military drones to the American troops in Iraq and Afghanistan - warzone. Therefore, the aerospace manufacturers in America shifted to create civilian market. The second factor responsible for the progress of local or civilian drones is that the US Congress overturned the ban on public and profitable UAVs and engaged the Federal Aviation Administration (FAA) to develop a strategy to include civil drones in the national airspace. The author's projection is that by the year 2030, civil and commercial UAVs will be flying. The author explains that the way in which America manages its domestic drones have become germane to the whole world as it opens up a competitive market because Europe, China and many other countries already have their shares of civilian markets.

However, the author states that while the Americans and Europeans produce high quality products for the media market, China offers a relatively cheap low-quality output to dominate the market. 
The author asserts that the advent of widely sought-after drone technology has brought about online 'PersonalDrone' groups which are devoted to open-source drone study and growth. Anderson founded the online group DIY Drones and the membership has grown worldwide. The author explains that this claim by Anderson to have been responsible for the enhanced personal drone movement in United States of America is doubtful. Be that as it may, the author affirms that Anderson is exceedingly central to the evolving 'personal drone' movement. This 'private buzz' crusade proposes the utmost reasonable and instant choices for news gathering in dangerous environments.

Australia is at the forefront or well known for adoption of operation regulation orchestrated by the Civil Aviation Safety Authority (CASA) which also accepted that the remarkable rapidity of high-tech progress and use had reduced those rules basically out of date. The speedy proliferation of drone technology also shows that CASA was grossly ineffective in implementing the guidelines as stipulated by the Australian Government. Therefore, a deregulation was considered necessary to meet the current realities which stipulates the minimum and maximum take-off weight for the craft. The author reveals that the officials were unable to meet the many limits or goals set for reorganizing the skill. The complexity is as a result of the vast areas which the technology by its definition covers; from pastime factory to multi-million dollar fighting intelligence gathering stages.

The author further states that as at December 2013, CASA permitted 66 marketable UAV workers in Australia covering areas such as aerial mapping and mine surveying, power line inspection, aerospace research, agricultural research, real estate photography, aerial filming of sports events.

However, no media organization had approval to operate drones in Australia; meanwhile, there was a rapid proliferation of cheap high-performing hobby craft such as Model Aircraft (MA). The author affirms that in 2013, the media organizations in Australia which legally adopted the use of drone technology had been on the increase. He added that ABC-TV's Four Corners engaged

a CASA approved operator to film sequences for a September 2013 report 'In Google We Trust' that surveyed social media skill and secrecy and the establishment of 'amateur' drone pictures of the Tasmanian Bushfire. Once again, a CASApermitted profitable worker was contracted by ABC-TV Sport and Events to fly a multi-rotor craft over Australian Day Flag Raising Ceremony in Camberra which provides aerial shots of the ABC's one hour live national broadcast of the event. According to the author, this was a significant 'proof of concept' that raises ABC's assurance in both the dependability of the expertise for covering important national 'Outside Broadcast' (OB) as well as safety. In addition, BBC and CNN have started using UAVs for international newsgathering assignments while Australian commercial TV
Networks Seven and Nine pebbledash limitations internally also used small drones overseas (Corcoran, 2014).

The author states that the use of drones for newsgathering offers two main benefits which are convenience and cost. In other words, drone technology offers a convenient low-cost aerial filming capability. Depending on their configuration, performance and camera, the author while making presentation to the Drone Power Conference in Camberra in July 2013 states that a small multi-rotor drone costs between $\mathrm{A} \$ 1,000$ - A $\$ 20,000$ while a news helicopter cost about $\mathrm{A} \$ 3.5 \mathrm{M}$.

Although UAVs have so much to offer to news gatherers, the technology is still new and growing.

The author states categorically that UAV technology still lacks "human element", that is, the ability of the media crew to observe and quickly react to a safety threat or to anticipate a break in development on a story which the pilots all the 'Eyeball Mark I'. In other words, it cannot do the job exactly as humans can do it. This limitation calls for further research by drone technology engineers and innovators (Corcoran, 2014).

\section{Definitions of Drone}

In trying to define the term drone, the author acknowledges that there are many definitions of the technology depending on the angle from which one looks at this piece of technology. Hence, it's definition has generated much public debate. Drone is described as a piece of technology that takes graphical records of events as they unfold or happen. The drone's name has generated a lot of debate as to when and how the UAV should be used. Ten years ago, it was defined or described as military aircraft without a pilot but has a target-towing. For the military many years ago, it was defined as 'a pilotless, radio-controlled military target-towing aircraft'. Currently, its popular description is "any craft that flies without a pilot at the controls, be it a direct control by an operator on the ground or which can fly without human involvement". Journalists call the emergence of this evolution or advancement in newsgathering a 'drone'. Nevertheless, the aviation professionals and government regulators have a strong opposition to the term 'drone'; they prefer a more multifaceted and theoretically accurate lexicon among which are:

$1 U A V$ which stands for Unmanned Aerial Vehicle and UAS which means Unmanned Aerial System; a UAV and the ground-based control system.

2 From the perspectives of the military forces in UK, US and Australia, they insist on using the terms RPA (Remotely Piloted Aircraft) and RPAS (Remotely Piloted Aircraft System).

3 The military pilots do not like the term 'drone' because it reduces their expertise in controlling the craft in the air; the word 'pilot' should be included. To them, a flying aircraft without a pilot is 
unimaginable! This is a strong position which also debunks the idea of, or the inclusion of "without human involvement" in the earlier definition.

4 The international and national civil aviation regulators including Australia's CASA are unable to settle for tag. The name 'drone' has evolved from UAV to UAS, now RPA/RPAS as directed by the International Civil Aviation Organization (ICAO) (Corcoran, 2014).

The author adds that many journalists have been upbraided by experts for failing to use the appropriate terms such as unmanned aerial vehicle (UAV) or unmanned aircraft system (UAS) or remotely piloted vehicle. The debate on the transition of 'drone' from military to civilian does not only generate conflict of interest in terms of expertise, it also has a potential to affect the huge civilian market for the manufacturers of the aircraft. Therefore, it is safe to state that the transition of drone technology from military to civilian use has both economic and professional underpinnings.

It is a 41-page report written by Mark Corcoran in January,2014. Mark Corcoran is anInternational Correspondent for Australian Broadcasting Corporation. In his introduction, the author narrated his first encounter with drone or Unmanned Aerial Vehicle (UAV) in 2006 when a bomb ravaged an apartment in south Beirut while he was reporting for Australian Broadcasting Corporation Television (ABC-TV) Foreign Correspondent program. He quoted Lambeth (2011) who described Israeli military operations against Hezbollah using "drones as an omnipresent force over Lebanon".

The author's report which was based on his experience in Iraq and Afghanistan, the major conflict environments categorized hazardous newsgathering assignments into Major Conflict. Civil Unrest, and Disaster Coverage. The author affirms that this introductory report Is not a "complex policy or technical document" rather it is written specifically for media executives, correspondents and news production teams. However, the author did not investigate the complicated range of "domestic safety" and "privacy issues", though they need to be addressed before "drone journalism" can be adopted for application in Australia, and of course in other parts of the world. The author's goal or plan is to explore these issues in a research degree thesis at the University of Technology, Sydney.

He further states that his report is not a multifaceted rule or practical document, rather it is written as a model for media executives, correspondents and news production teams. He explains that the issues of security and confidentiality are not considered in this though they are necessary and should be resolved before "drone journalism" can be put to use in Australia. He intends to look into the aspect of safety and privacy in his next study or research. The implication is that, it is an eye-opener for other nations and media organizations that intend to adopt drone technology for civil use (Corcoran, 2014).

\section{DATA ANALYSIS AND DISCUSSION OF MAJOR FINDINGS}

According to the report, Michael Cox, a former ABC-TV ( $\mathrm{ABC}$ stands for Australian Broadcasting Corporation) and a current ABC-TV Acting Production Resources Manager, who also has a vast experience in conflict newsgathering is featured in this introductory paper. Michael Cox is charged with the responsibility for assessing and acquiring the new newsgathering technology. The report featured another personality called retired Lieutenant Colonel Philip Swinsburg. Lt Colonel Philip Swinsburg played a vital role in the introduction of what the author described as the small "Tactical UAV" surveillance capability for the Australian Defence Force in Iraq and Afghanistan. Lt. Colonel Philip Swinsburg (rtd) since his retirement has been working in a commercial Sector as Managing Director of Unmanned System Australia. This implies that the adoption of UAV requires sufficiently experienced personnel in the use of drones. The distinguished experts are drawn from both the military, civil aviation experts and media managers (Corcoran, 2014).

The paper addressed many aspects of the "drone journalism" based on his over a decade experience. The definition of "Dogfight", "Kicking the Tyres" which outlines the four (4) broad categories of drones suitable for newsgathering have been expressly addressed. Another very important aspectof the review is that the Major Conflict and Military Embeds whereby journalists or media workers can work independently or they can be 'embedded' or joined with the military patrol, the "Disposable Drone" concept, ABC-TV Foreign Correspondent - Informal Proof of Concept - Afghanistan, Case Study Lessons, Implications of Deploying Media Drones over civil communities during conflict, Other Risks for Media Drone Operations in Conflict, Potential Sovereignty issues, Revolution and civil unrest, Drone Journalism in an Urban Environment, Disaster Coverage, Daily Drone, Fukushima, The Lithgow-Blue Mountains Bushfire, ABC News the Tasmanian Bushfires, and $\mathrm{ABC}$ - Emergency Broadcaster. This shows that the concept of UAV, UAS, or drone technology is broad-based and multifaceted. Its universal nature and need call for so much to be done in this everevolving piece of technology that has the capacity to do what is humanly impossible for human journalists to do such as covering wars, natural and manmade disasters such as insurgency, terrorism, banditry and so on. Privacy and regulation issues also require adequate attention to ensure that both national and international guidelines or rules are strictly adhered or followed.

The author outlined four (4) broad categories of drones which are suitable for newsgathering. They Include but not limited to: 
1 Small Helicopter-like 'Multi-rotors': This is most suitable for immediacy, but has less picture quality. Light weight, easy to operate with the use of $\mathrm{Wi}-\mathrm{Fi}$ and relatively cheap.

2 Larger Multi-Rotor: heavier, higher quality picture resolution and more expensive than Small Helicopterlike Multi-rotors. It is suitable for drone journalism in urban areas.

3 Small Fixed Wing Craft: this is more like large model aircraft, requires antenna to operate and it is suitable for longer range regional or coastal newsgathering assignments. It is quite expensive subject to its sophistication.

4 Long Range Fixed-Wing Craft: this is the most sophisticated among the four; it is suitable for both military and civilian use. Capable of hosting three to four skilled crew members, highly complex and expensive. (Corcoran, 2014).

The contemporary era of newsgathering and reporting is characterized by both natural and man-made disasters globally. Natural disasters such as flood, tsunamis, wildfire, earthquakes occur almost on a daily basis as well as the manmade disasters such as wars, terrorism, violence, conflicts and so on. The journalist is faced with the ever-increasing demands for objective and factual report of the incidences of natural and man-made events. This requires adoption of the drone technology as quickly as possible which is in line with the main assumption of the Diffusion of Innovation Theory (Rogers, 1962, 2003). They are everywhere from America to United Kingdom, Asia, Africa and Nigeria is not left out in the disasters that bedevil the whole world on a daily basis.

When disasters or events occur, journalists are expected to diligently seek for, gather, process and report them to the yearning audience. In doing this, many journalists have lost their lives due to the dangers they are confronted with in the course of their legitimate duty of newsgathering and reporting. What then is the solution to the daunting challenges being faced byjournalists? For instance, during the \#ENDSARS protest and the eventual Lekki Gate saga in Nigeria, such incidence and the likes, example insurgency (Boko Haram menace, armed banditry and kidnapping) require journalists to cover and report to the public. The safety of journalists in gathering facts and reporting such incidences become great concerns to the journalists, the media organizations and the society at large. This paper has analytically reviewed the concept of aerial newsgathering and reporting in the contemporary era and has found that unmanned aerial vehicles (UAVs) or drone technology has the capacity to do the work effectively without endangering human journalists on the line of duty.

\section{RECOMMENDATIONS}

Based on the review, the following recommendations are made:
1 Media organizations should do all within their power to adopt drone technology for newsgathering and reporting to reduce the hazards associated with the contemporary era of journalism.

2 There should be a collaborative effort between and among the military, the media, the Federal Aviation Authority (FAA), the legislators to formulate appropriate policy for adoption of UAVs or drones for journalism practice in Nigeria.

3 The media should be proactive in the training of their journalists in the use of drones or UAVs for effective service delivery.

4 More research should be done in this relatively new concept, particularly in developing nations to ensure that more awareness is created about the many challenges of using drones for newsgathering and reporting.

5 More work should be done on the likely dangers of using drones.

\section{CONCLUSION}

The emergence of drones and its adoption, challenges, and the numerous benefits it offers are exhaustively reviewed and recommendations made. Drone technology has a lot of merits for media organizations or workers who are on a high risky or hazardous assignment. However, journalists are advised not to be swept off balance while adopting this piece of awesome technology and its amazing many benefits. The human angle to a story such as direct personal contact, gathering information and gauging mood, context and accuracy remain the hallmarks of journalism practice which cannot be achieved or realized remotely. Nevertheless, 'lone drone is still the panacea for safety of newsgatherers in hostile environments. Editorial decisions and storytelling methods are not likely to be influenced by the transformative power of drone technology. The emergence of drone technology would not create a distinct or new media genre, but rather an addition to the many technological evolutions in newsgathering, processing and reporting in the contemporary era.

\section{REFERENCES}

[1] Corcoran, M. (2014). Drone Journalism: Newsgathering Application of Unmanned Aerial Vehicles (UAVs) in Covering Conflict, Civil Unrest and Disaster.

[2] FAA (2010), FAA Aerospace Forecast Fiscal Year 2010-2030. Washington DC, Viewed September 5, 2021,http://www.faa.gov.data research/aviation/aerospace forecasts/2010-2030/media/2010\%20forecast\%20Doc.pdf

[3] Rogers E. (1962). Diffusion of Innovations. Free Press, London, NY, USA

[4] Noel, H. (2009). Consumer Behaviour. Lausanne, Switzerland La Vergne, TN: AVA Academia Distributed in the USA by Ingram Publisher Services. ISBN 9782940439249.

[5] Stone, D. (2004). "Transfer agents and global networks in the 'transnationalization' of policy" (PDF). Journal of European Public Policy (Submitted manuscript). 11 (3): 545-

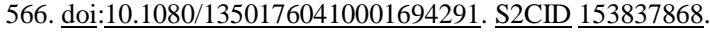


[6] He X K, Bonds J, Herbst A, Langenakens J. Recent development of unmanned aerial vehicle for plant protection in East Asia. Int $\mathrm{J}$ Agric \& Biol Eng, 2017; 10(3): 18-30.

[7] https://defense.info/partners-corner/2020/01/south-african-uses-ofdrones 28/01/2020 · South African Uses of Drones 01/28/2020 By defence Web Unmanned Aerial Vehicles (UAVs), also known as drones, have applications in multiple industries due to their ability
[8] Ahmed, A.(2021). Zayed University, United Arab Emirates. Conference: MediAsia 2021 Stream: Digital Media and Use of New Technology in Newsgathering.

[9] Lauk, E., Uskali, T., Kuutti, H. \&Hervinen, H. (2016). Drone Journalism: The Newest Global Test of Press Freedom. In: Freedom of Expression and Media in Transition: Studies and Reflections in the Digital Age. Ed. By Ulla Carisson. Gothenburg: NORDICOM, 117-125. 